\title{
PENGARUH METODE LATIHAN SISTEM SET DAN SIRKUIT TERHADAP PENINGKATAN KEMAMPUAN DAYA LEDAK OTOT LENGAN PADA ATLET BOLABASKET FIK UNP
}

\author{
Sari Mariati ${ }^{1}$, Willady Rasyid ${ }^{2}$ \\ ${ }^{1}$ Program Studi Pendidikan Kepelatihan Olahraga Universitas Negeri Padang. \\ Jalan Prof.Dr.Hamka Air Tawar Barat, Padang, 25132, Indonesia. \\ ${ }^{2}$ Program Studi Pendidikan Olahraga Universitas Negeri Padang. Jalan Prof.Dr.Hamka Air Tawar \\ Barat, Padang, 25132, Indonesia. \\ Email: sari mariati@ fik.unp.ac.id
}

\begin{abstract}
Abstrak
Penelitian ini bertujuan untuk melihat ada atau tidak adanya perbedaan pengaruh sistem set dan sistem sirkuit terhadap peningkatan daya ledak otot lengan pada atlet FIK UNP Padang. Jenis penelitian ini adalah penelitian exsperimen semu yang dilakukan di GOR PPSP Pembangunan UNP. Sampel penelitian ini adalah pemain bolabasket putra FIK UNP yang berjumlah 20 orang dan terdiri dari 10 orang kelompok sistem set dan 10 orang kelompok sistem sirkuit yang diberikan perlakuan 16 kali latihan. Teknik pengambilan data menggunakan two hand medicine ball push. Data yang telah terkumpul digunakan untuk menguji hipotesis yang menggunakan uji t. Sebelum uji t dilakukan terlebih dahulu dilakukan uji persyaratan analisis yaitu uji normalitas dan uji homogenitas. Hasil dari uji hipotesisi 1,2, dan 3 yang menggunakan statistik uji t dapat disimpulkan sebagai berikut : (1) Sistem set tidak berpengaruh secara signifikan terhadap peningkatan kemampuan daya ledak otot lengan dapat diperoleh nilai $t_{\text {hit }} 1.74<\mathrm{t}_{\text {tab }} 2.26$ dan p $0.11>0.05 \alpha$ (2) Sistem sirkuit berpengaruh secara signifikan terhadap peningkatan kemampuan daya ledak otot lengan dapat diperoleh nilai $t_{\text {hit }}$ $10.30>\mathrm{t}_{\mathrm{tab}} 2.26$ dan $\mathrm{p} 0.00<0.05 \alpha$ (3) Tidak terdapat perbedaan pengaruh secara signifikan antara sistem set dan sistem sirkuit terhadap peningkatan kemampuan daya ledak otot lengan dapat diperoleh nilai $\mathrm{t}_{\text {hit }} 1.32<\mathrm{t}_{\mathrm{tab}} 2.26$ dan $\mathrm{p} 0.287>0.05 \alpha$.
\end{abstract}

Kata Kunci : Sistem set, sistem sirkuit, kemampuan daya ledak otot lengan pada atlet bolabasket FIK UNP

\begin{abstract}
This study aims to see whether or not there is a difference in the influence of the set system and circuit system on the increase in arm muscle explosive power in UNP Padang FIK athletes. This type of research is a quasi-experimental research conducted at the PPSP GOR of UNP Development. This study aims to see whether or not there is a difference in the influence of the set system and circuit system on the increase in arm muscle explosive power in UNP Padang FIK athletes. The type of this research was a quasi-experimental study conducted at the PPSP National Development Development Center in the sample. The research was 20 male football players from FIK UNP and consisted of 10 sets of system groups and 10 circuit system groups who were given 16 exercises Data collection techniques using two hand medicine ball push. The collected data is used to test hypotheses using the $\mathrm{t}$ test. Before the $\mathrm{t}$ test is carried out, the analysis requirements test is carried out, namely the normality test and homogeneity test. The results of the 1.2, and 3 hypothesis test using t test statistics can be summarized as follows: (1) The set system does not significantly influence the increase in arm muscle explosive ability. It can be obtained thit $1.74<\operatorname{ttab} 2.26$ and $\mathrm{p} 0.11>0.05 \alpha$. $>$ tt 2.26 and $\mathrm{p} 0.00$ $<0.05 \alpha$ (3) There is no significant difference in effect between the set system and the circuit system on the increase in arm muscle explosive ability, the value of thit $1.32<2.26$ and $p 0.287>0.05 \alpha$.
\end{abstract}

Keywords : System set, circuit system, arm muscle explosive ability in basketball athletes FIK UNP.

\section{Pendahuluan}

Menurut PB. PERBASI (2008), permainan bolabasket adalah suatu permainan yang dimainkan oleh dua regu putera atau puteri yang masing-masing regu terdiri dari lima orang pemain dengan menggunakan lapangan permainan berbentuk persegi panjang dengan ukuran $28 \mathrm{~cm} \times 15 \mathrm{~cm}$ dan bola yang terbuat dari karet yang berlapis sejenis kulit dengan keliling 75-78 cm, dengan berat $600-650$ gram. 
Sedangkan konsep bermain bolabasket menurut Tomoliyus (2001:11) adalah: menghasilkan skor (nilai) dengan memasukkan bola ke keranjang (basket) dan mencegah tim lain melakukan hal serupa. Permainan bolabasket merupakan olahraga yang memiliki aktivitas gerak yang menuntut berbagai keterampilan, teknik dan taktik disamping kondisi yang prima bagi pelakunya. Disamping itu permainan bolabasket menuntut kreativitas teknik, keberanian untuk berbuat sesuatu dan kepercayaan akan kemampuan sendiri dan kerjasama tim yang baik.

Seperti yang dikemukakan oleh Frank S. Pyke dalam PENGDA PERBASI (2005:12) bahwa: "Basketball is a game of habbit, artinya permainan bolabasket adalah olahraga yang berdasarkan kebiasaan".

Dari uraian di atas dimaksudkan bahwa permainan bolabasket adalah olahraga yang berdasarkan kebiasaan, artinya untuk menjadi seorang pemain bolabasket yang baik sangat dibutuhkan proses latihan atau bermain secara berulang-ulang atau berkelanjutan (continue) agar memperoleh teknik, taktik dan kondisi prima dalam permainan yang bagus. Kemudian menurut Bompa dalam Syahara (2005:56) mengemukakan bahwa : untuk menjadi seorang atlet dicabang olahraga bolabasket dapat dimulai dari usia dini yaitu 7-8 tahun. Dalam olahraga permainan bolabasket, usia latihan spesialisasi dimulai pada umur 12-19 tahun, sedangkan usia pencapaian puncak prestasi usia 20-25 tahun, atlet bolabasket lebih matang dalam mengatur strategi dan teknik permainan.

Menurut Witarsyah (2005:5) mengatakan bahwa : passing adalah keahlian mendasar yang sangat penting dipelajari oleh setiap pemain bolabasket. Passing merupakan salah satu kunci keberhasilan serangan sebuah tim dan sebuah unsur penentu tembakantembakan yang berpeluang besar mencetak angka. Ketepatan passing yang hebat tidak boleh diremehkan. Ini bisa memotivasi rekan-rekan tim, menghibur penonton dan menghasilkan permainan yang tidak individualis. Jon dalam Wawan (2007:38) mengemukakan bahwa : Dalam passing (mengumpan) dapat dilakukan beberapa macam teknik yaitu : chest pass (umpan dada), bounce pass (umpan pantul), two-handed overhead (umpan atas kepala menggunakan dua tangan), baseball (umpan bisbol/lemparan samping), shuffle pass (umpan sambil berlari), dribble pass (umpan dribble), wrap-around (umpan selubung) dan behind the back (umpan di belakang punggung).

Masing-masing passing memiliki kegunaan khusus dalam situasi pertandingan yang berbeda-beda. Dalam penelitian ini akan dilakukan pada kemampuan passing dada (chest pass). Menurut Ambler (1982:25): "mengoperkan bola dari posisi setinggi dada merupakan teknik yang paling sering dipakai dalam permainan biasa". Teknik mengoperkan bola setinggi dada ini disebut demikian karena memang bola dilempar dari daerah di depan dada pemain.

Apabila pelaksanaan passing dada (chest pass) berjalan dengan lancar sehingga terciptanya kerjasama tim yang baik dan dapat mengendalikan tempo permainan sehingga mudah untuk menciptakan peluang demi peluang untuk melakukan shooting dan akhirnya poin demi poin terkumpul, maka terciptalah suatu kemenangan. Oleh sebab itu passing dada (chest pass) merupakan salah satu teknik dasar penentu kemenangan di dalam cabang olahraga bolabasket).

Berdasarkan kutipan-kutipan di atas, dapat dikemukakan bahwa kemampuan passing dada (chest pass) merupakan salah satu kemampuan teknik dasar passing dalam permainan bolabasket yang penting peranannya untuk mengatur tempo permainan, mengadakan serangan balik, melewati lawan serta membuat kesempatan untuk melakukan tembakan dan dapat menjaga bola tetap berada di pihak sendiri.

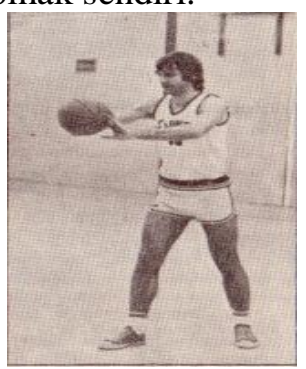

Gambar 1: Bentuk Pelaksanaan Chest pass

(Ambler, 1982:24-29).

Daya ledak merupakan salah satu dari komponen biomotorik yang penting dalam kegiatan olahraga, karena daya ledak akan menentukan seberapa jauh melempar bola dan sebagainya.

Menurut Bompa dalam Syahara (2004: 20-23) daya ledak (power) merupakan hasil dari dua kemampuan yaitu kekuatan dan kecepatan dan dipertimbangkan sebagai suatu kemampuan untuk menampilkan kekuatan yang maksimum dalam waktu yang paling pendek. 
Daya ledak otot lengan merupakan kemampuan dasar kondisi fisik yang merupakan tumpuan utama dalam pencapaian prestasi bolabasket, khususnya dalam melakukan passing dada (chest pass). Perolehan poin (angka) tidak akan dapat tercipta apabila passing dada (chest pass) yang dilakukan tidak sampai atau berjalan dengan lancar kepada pemain yang berada pada posisi bebas untuk melakukan shooting ke ring basket. Passing dada (chest pass) merupakan salah satu teknik dasar dalam menyusun strategi penyerangan.

Selanjutnya Nossek dalam Asril (1999:74) menyatakan bahwa faktor yang mempengaruhi daya ledak adalah kekuatan dan kecepatan kontraksi. Sedangkan menurut Herre dalam Asril (1999:74) menyatakan bahwa faktor yang mempengaruhi kekuatan otot sebagai daya ledak adalah jenis serabut otot, luas otot rangka, jumlah cross bridge, sistem metabolisme energi, sudut sendi dan aspek psikologis.

Berdasarkan kutipan-kutipan di atas, dapat disimpulkan bahwa daya ledak otot lengan merupakan kemampuan otot lengan untuk menampilkan kekuatan maksimum dan kecepatan maksimum secara eksplosive dalam waktu cepat dan singkat untuk mencapai tujuan yang dikehendaki sehingga otot lengan yang menampilkan gerakan eksplosive ini sangat kuat dan cepat dalam berkontraksi serta dipengaruhi oleh faktor-faktor tertentu seperti sistem metabolisme energi dan lain sebagainya.

a. Otot-otot yang terlibat dalam gerakan chest pass

Adapun otot-otot lengan yang sangat berperan sekali dalam melakukan passing dada (chest pass) pada cabang olahraga permainan bolabasket menurut Basoeki (1988:28) adalah :

Untuk lebih jelasnya gambar otot-otot lengan dapat dilihat pada gambar di bawah ini :

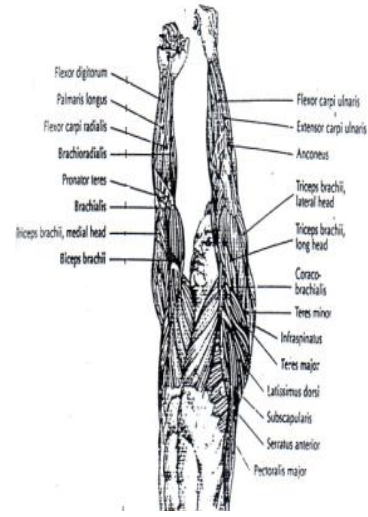

Gambar 2: Otot-otot lengan yang dominan digunakan dalam pelaksanaan passing (Delavier, 2001 : 63)

\section{b. Sistem Energi}

Nawawi (2008:1) menyatakan bahwa energi adalah kapasitas untuk melakukan kerja (work of capacity). Kerja merupakan hasil perkalian antara tenaga (force) dengan jarak (distance). Semakin berat suatu pekerjaan maka semakin banyak kebutuhan energi.

Selanjutnya, Syahara menyatakan bahwa seluruh energi yang dipakai dalam dunia biologis pada dasarnya bersumber dari matahari. Sumber energi yang dapat dengan segera digunakan untuk setiap aktivitas manusia seperti pada sistem biologis datang dari pemecahan senyawa kimia tunggal $\rightarrow$ ATP (Adenosine Triphospate). Metabolisme produksi ATP otot dan sel berasal dari pembebasan energi melalui pemecahan zat makanan dan senyawa lain yang melibatkan serangkaian reaksi kimia anaerobik maupun aerobik (karbohidrat, selulosa, protein dan lemak). Untuk otot yang bekerja, maka sistem energinya tergantung dari intensitas dan jangka waktu yang digunakan dalam kegiatan yang dilakukan.

Berdasarkan kutipan-kutipan di atas sumber energi yang paling utama akan mempengaruhi proses yang lain adalah energi yang berasal dari matahari. Energi kimia dapat diubah menjadi energi mekanik yang akan menghasilkan gerak. Untuk melakukan berbagai aktivitas tubuh memerlukan gerak, gerak dihasilkan dari kontraksi dan relaksasi otot rangka, untuk bisa bekerja otot rangka memerlukan energi, energi diambil dari pemecahan bahan kimia di dalam otot yaitu ATP (Adenosine Triphosphate).

Selanjutnya Nawawi

menyatakan bahwa :

Sistem energi dalam aktivitas fisik terdiri dari dua bagian yaitu sistim anaerobik dan sistim aerobik. Sistim anaerobik adalah proses metabolisme energi tanpa menggunakan oksigen, sedangkan sistim aerobik adalah proses metabolisme energi dengan menggunakan oksigen. Kedua sistim energi ini terdapat di dalam semua cabang olahraga, hanya predominant system nya yang berbeda-beda tergantung dari intensits, waktu, jarak dan frekuensi dari aktivitas tersebut. Pada cabang olahraga yang intensitasnya tinggi, maka sistim energinya lebih dominan anaerobik, sebaliknya cabang olahraga dengan intensitas yang rendah, maka sistim energinya lebih dominan aerobik. 
c. Ciri - ciri latihan (power) daya ledak Harsono (1993:13-14) mengatakan:

1) Melawan beban berat badan sendiri atau tambahan beban luarrelatif ringan.

2) Gerakan latihan dinamis dan cepat.

3) Gerakan merupakan gerakan yang utuh, singkat dan harmonis.

4) Bentuk bahan latihan cyclic atau acyclic.

5) Intensitas sub maksimal atau maksimal.

d. Prinsip - prinsip yang harus diperhatikan dalam latihan daya ledak

Menurut Harsono (1993: 14), Prinsip-prinsip dalam latihan daya ledak adalah:

1) Volume beban latihan dalam 1 sesi latihan $4-6$ set.

2) Intensitas submaksimal atau maksimal, beban yang diangkat (berat barbell) 1/4

- 1/3 berat badan atlet.

3) Ulangan angkatan per - set 12-15 kali.

4) Recovery antar set $2-3$ menit.

\section{Hakekat Metode Latihan}

Latihan adalah aktivitas atau kegiatan yang terdiri dari berbagai bentuk sikap dan gerak, terarah, berulang-ulang, dengan beban yang kian bertambah guna memperbaiki efisiensi kemampuan. Menurut Bompa (1994:2) "latihan merupakan proses pengulangan yang sistematis, progresif dengan tujuan akhir memperbaiki prestasi olahraga. Kunci utama dalam memperbaiki prestasi olahraga adalah sistem latihan yang diorganisasikan secara baik. Program latihan harus mengikuti konsep periodesasi, disusun dan direncanakan secara baik berdasar cabang olahraga, agar sistem energi atlet mampu beradaptasi terhadap kekhususan cabang olahraga".

Metode latihan menurut Syafruddin (1996:104) adalah cara-cara yang digunakan secara terencana dan sistimatis dan terorientasi pada tujuan. Bachtiar (1995:19) menambahkan bahwa metode latihan adalah cara mengajarkan khusus yang digunakan dalam mengelola pengetahuan prinsip-prinsip dan norma-norma yang berlaku dalam olahraga atau semua yang penting dalam proses belajar motorik untuk tercapainya tujuan dan keefektifan dalam belajar.

a. Metode latihan sistim set

Menurut Harsono (1988:196) metode latihan sistim set adalah latihan yang menggunakan beberapa repetisi suatu bentuk latihan kemudian disusul dengan suatu masa istirahat, selanjutnya melakukan lagi repetisi semula (gerakan yang sama), ada yang melakukan 2 set untuk suatu bentuk latihan ada pula yang melakukan 3 set.
Kemudian Ambeim dalam Afdal (1991:3) menjelaskan bahwa program latihan 3 set setiap kerjanya menghasilkan peningkatan kekuatan yang terbesar dari pada memakai program latihan 1 atau 2 set. Dalam pelaksanaan latihan sistim set ini, dijelaskan oleh Fall dkk dalam Afdal (1991:1) bahwa jumlah pengulangan dalam satu set tidak lebih dari 12 dan tidak kurang dari 6 kali pengulangan.

Metode latihan sistim set juga terdapat istirahat, Sajoto dalam Yendrizal (1997:27) menjelaskan sistim set ini perlu memberikan kesempatan kepada otot untuk beristirahat, maka antara set satu ke set berikutnya harus ada waktu istirahat antara 1-2 menit.

Metode latihan sistem sirkuit

Selain metode latihan sistim set, juga ada metode latihan yang pertama kali diperkenalkan oleh Morgan dan Adamson pada tahun 1953 di Universitas of Leed di Inggris, yaitu sistem sirkuit.

Sistem sirkuit menurut Fox dalam Yendrizal (1997:24) adalah latihan yang terdiri dari 6 - 15 pos tempat latihan. Satu kali latihan dalam stasiun diselesaikan dalam waktu 30 detik, satu sirkuit diselesaikan antara 5-20 menit dan istirahat tiap pos adalah 5 - 20 detik. Menurut Sodikoen (1991:62) bentuk latihan sirkuit disusun dalam bentuk lingkaran, mulai dari pos I, II, III dan seterusnya disusun berurutan mengelilingi arena (lapangan). Dalam latihan sirkuit atlet harus melalui pos demi pos yang telah ditentukan dan tidak boleh melampaui pos berikutnya. Selanjutnya Soedikoen (1991:65) kembali menjelaskan satu sirkuit telah dianggap selesai apabila atlet telah menyelesaikan latihan di setiap pos sesuai dengan target waktu yang telah ditetapkan.

Pada metode latihan sistem sirkuit, bentuk latihan kondisi fisik untuk teknik pelaksanan latihan tidak cara pelaksanaan tidak berbeda dengan sistem set, namun pada sistem ini atlet diharuskan menyelesaikan bentuk latihan pada satu pos kemudian pindah pada pos berikutnya pada pos terakhir. Setiap atlet harus melaknanakan gerakan disetiap pos secara berurutan . setelah menyelesaikan 1 set kemudian istirahat dan melakukan kembali hingga sampai 3 set. Jadi,secara sederhana metoda latihan sistem sirkuit dapat digambarkan yaitu $10 \times 3$ set (jumlah pos $\times$ jumlah set) .dengan cara latihan seperti ini akan terjadi pengaruh pada peningkatan kondisi fisik atlet yang mendukung kemampuan chest pass pada bolabasket tepatnya sistem sirkuit diharapkan 


\begin{tabular}{|c|c|c|c|c|c|c|}
\hline \multirow{2}{*}{$\begin{array}{l}\mathbf{N} \\
\mathbf{O} \\
\text {. }\end{array}$} & \multirow{2}{*}{ NAMA } & \multicolumn{2}{|c|}{ SISTIM SET } & \multicolumn{2}{|c|}{$\begin{array}{c}\text { SISTIM } \\
\text { SIRKUIT }\end{array}$} & \multirow{2}{*}{ NAMA } \\
\hline & & $\begin{array}{l}\text { PRE- } \\
\text { TEST }\end{array}$ & $\begin{array}{c}\text { POST- } \\
\text { TEST }\end{array}$ & $\begin{array}{l}\text { PRE- } \\
\text { TEST }\end{array}$ & $\begin{array}{c}\text { POST- } \\
\text { TEST }\end{array}$ & \\
\hline 1. & RONI & $\begin{array}{l}5.5 \\
\mathrm{mtr}\end{array}$ & $6 \mathrm{mtr}$ & $\begin{array}{l}5.3 \\
\mathrm{mtr}\end{array}$ & $5.6 \mathrm{mtr}$ & $\begin{array}{l}\text { ANTO } \\
\mathrm{N}\end{array}$ \\
\hline 2. & IHSAN & $5 \mathrm{mtr}$ & $4.5 \mathrm{mtr}$ & $5 \mathrm{mtr}$ & $5.5 \mathrm{mtr}$ & $\begin{array}{l}\text { KOME } \\
\mathrm{T}\end{array}$ \\
\hline 3. & $\begin{array}{l}\text { SUSAN } \\
\text { TO }\end{array}$ & $\begin{array}{l}4.8 \\
\mathrm{mtr}\end{array}$ & $5.4 \mathrm{mtr}$ & $\begin{array}{l}4.8 \\
\mathrm{mtr}\end{array}$ & $5.2 \mathrm{mtr}$ & $\begin{array}{l}\text { ANDI } \\
\text { KA } \\
\end{array}$ \\
\hline 4. & RANDY & $\begin{array}{l}4.5 \\
\mathrm{mtr}\end{array}$ & $4.5 \mathrm{mtr}$ & $\begin{array}{l}4.6 \\
\mathrm{mtr}\end{array}$ & $5 \mathrm{mtr}$ & $\begin{array}{l}\text { YUVI } \\
\mathrm{A}\end{array}$ \\
\hline 5. & $\begin{array}{l}\text { BONIE } \\
\mathrm{K}\end{array}$ & $\begin{array}{l}4.5 \\
\mathrm{mtr}\end{array}$ & $4.5 \mathrm{mtr}$ & $\begin{array}{l}4.3 \\
\mathrm{mtr}\end{array}$ & $4.5 \mathrm{mtr}$ & RURY \\
\hline 6. & $\begin{array}{l}\text { RAHM } \\
\text { AN }\end{array}$ & $\begin{array}{l}4.2 \\
\mathrm{mtr}\end{array}$ & $5 \mathrm{mtr}$ & $\begin{array}{l}4.2 \\
\mathrm{mtr}\end{array}$ & $4.5 \mathrm{mtr}$ & $\begin{array}{l}\text { AZHA } \\
\text { RI }\end{array}$ \\
\hline 7. & ARIEF & $\begin{array}{l}4.2 \\
\mathrm{mtr}\end{array}$ & $4.5 \mathrm{mtr}$ & $\begin{array}{l}4.2 \\
\mathrm{mtr}\end{array}$ & $4.5 \mathrm{mtr}$ & ERY \\
\hline 8. & REZKY & $4 \mathrm{mtr}$ & $4.4 \mathrm{mtr}$ & $\begin{array}{l}4.1 \\
\mathrm{mtr}\end{array}$ & $4.5 \mathrm{mtr}$ & $\begin{array}{l}\text { DAVI } \\
\text { D }\end{array}$ \\
\hline 9. & DEDI & $4 \mathrm{mtr}$ & $4 \mathrm{mtr}$ & $\begin{array}{l}3.9 \\
\mathrm{mtr}\end{array}$ & $4.5 \mathrm{mtr}$ & NICO \\
\hline 10 & VEBI & $\begin{array}{l}3.2 \\
\mathrm{mtr}\end{array}$ & $3.2 \mathrm{mtr}$ & $\begin{array}{l}3.5 \\
\mathrm{mtr}\end{array}$ & $4 \mathrm{mtr}$ & $\begin{array}{l}\text { FERR } \\
\mathrm{Y} \\
\end{array}$ \\
\hline & $\sum$ & $\begin{array}{l}43.9 \\
\text { mtr }\end{array}$ & $46 \mathrm{mtr}$ & $\begin{array}{l}43.9 \\
\text { mtr }\end{array}$ & $\begin{array}{l}47.8 \\
\mathrm{mtr}\end{array}$ & $\sum$ \\
\hline
\end{tabular}

dapat memberi pengaruh pada peningkatan kemampuan daya ledak otot lengan pada atlet bolabasket.

\section{Metode Penelitian}

Jenis yang digunakan dalam penelitian ini adalah penelitian eksperimen semu. Penelitian ini dilaksanakan di GOR PPSP Pembangunan UNP. Populasi penelitian ini adalah atlet-atlet tim B putera bolabasket Fakultas Ilmu Keolahragaan UNP yang berusia 19-24 tahun yang berjumlah 25 orang.. Populasi penelitian ini adalah atlet-atlet tim B putera bolabasket Fakultas Ilmu Keolahragaan UNP yang berusia $19-24$ tahun yang berjumlah 25 orang.. Instrumen dilakukan dengan melakukan tes terhadap pemain bolabasket yang dijadikan sampel. Tes dilakukan dengan cara mengukur kemampuan daya ledak otot lengan yaitu dengan tes "two hand medicine ball-push"

\begin{tabular}{|c|c|c|c|c|c|c|c|}
\hline & $\mathrm{N}$ & $\begin{array}{l}\text { Mini } \\
\text { mum }\end{array}$ & $\begin{array}{r}M a \\
x i m \\
\text { um }\end{array}$ & Sum & $\begin{array}{r}M e a \\
n\end{array}$ & & $\begin{array}{r}\text { Std } . \\
\text { Deviation }\end{array}$ \\
\hline & $\begin{array}{r}\text { Sta } \\
\text { tist } \\
\text { ic }\end{array}$ & $\begin{array}{r}\text { Stati } \\
\text { stic }\end{array}$ & $\begin{array}{r}\text { Stat } \\
\text { isti } \\
c\end{array}$ & Statistic & $\begin{array}{r}\text { Stati } \\
\text { stic }\end{array}$ & $\begin{array}{r}\text { Std } \\
. \\
\text { Err } \\
\text { or }\end{array}$ & Statistic \\
\hline $\begin{array}{l}\text { DOL AWAL } \\
\text { SISTIM SET }\end{array}$ & 10 & 3.2 & 5.5 & 43.9 & $\begin{array}{r}4.39 \\
0\end{array}$ & $\begin{array}{r}.20 \\
0\end{array}$ & .631 \\
\hline $\begin{array}{l}\text { DOL } \\
\text { AKHIR } \\
\text { SISTIM SET }\end{array}$ & 10 & 3.2 & 6.0 & 46.0 & $\begin{array}{r}4.60 \\
0\end{array}$ & $\begin{array}{r}.23 \\
9\end{array}$ & .757 \\
\hline $\begin{array}{l}\text { DOL AWAL } \\
\text { SISTIM } \\
\text { CIRCUIT }\end{array}$ & 10 & 3.5 & 5.3 & 43.9 & $\begin{array}{r}4.39 \\
0\end{array}$ & $\begin{array}{r}.17 \\
0\end{array}$ & .538 \\
\hline $\begin{array}{l}\text { DOL } \\
\text { AKHIR } \\
\text { SISTIM } \\
\text { CIRCUIT } \\
\end{array}$ & 10 & 4.0 & 5.6 & 47.8 & $\begin{array}{r}4.78 \\
0\end{array}$ & $\begin{array}{r}.16 \\
4\end{array}$ & .518 \\
\hline $\begin{array}{l}\text { Valid N } \\
\text { (listwise) }\end{array}$ & 10 & & & & & & \\
\hline
\end{tabular}

(Nurhasan, 1984 : 57), dengan koefisien realibilitas tes sebesar 0,81 dan validitas 0,77 serta objektivitas 0,99 .

Pendeskripsian data dan pengujian hipotesis dalam penelitian ini diolah dengan memakai statistik deskriptif dan inferensial dengan rumus uji t sampel terikat. Sebelum dilakukan analisis uji t, terlebih dahulu dilakukan uji persyaratan analisis, yaitu normalitas data dan homogenitas, dan uji $\mathrm{t}$ hanya dapat digunakan untuk menguji perbedaan mean dari dua sampel yang diambil dari populasi yang normal dan kelompok yang homogen (Isparjadi : 1998).

Setelah uji normalitas dilakukan, maka dilakukan analisis uji t, dengan rumus sebagai berikut :

$$
\mathrm{t}=\frac{\left|\overline{\mathrm{X}_{1}}-\overline{\mathrm{X}_{2}}\right|}{\sqrt{\frac{\sum \mathrm{D}^{2}-\frac{(\Sigma \mathrm{D})^{2}}{\mathrm{~N}}}{\mathrm{~N}(\mathrm{~N}-1)}}}
$$

\section{Hasil Penelitian dan Diskusi}

Data dalam penelitian ini merupakan data primer yaitu daya ledak otot lengan yang diukur dengan menggunakan bola medisin (medicine ball).

Tabel 3. Deskripsi Data Daya Ledak Otot Lengan Sistem Set dan Sistem Sirkuit

Selanjutnya data-data tersebut di atas dianalis dengan statistik deskriptif, dan hasilnya dapat dilihat pada tabel berikut ini;

\section{Tabel 4. Statistik Deskriptif Data} Penelitian 
Berdasarkan pada tabel di atas dapat dilihat bahwa; untuk kelompok 1 yang akan diberi perlakuan sistim set, hasil tes awal memiliki nilai tertinggi 5.5 meter, nilai terendah 3.2 meter, dan nilai rata-ratanya adalah 4.39 meter. Sedangkan kelmpok 2 yang akan diberikan perlakuan sistim sirkuit memiliki niali tertinggi 5.3 meter, nilai terendah 3.5 meter, dan nilai rata-ratanya 4.39 meter. Selanjutnya setelah diberikan perlakuan pada kedua kelompok maka, untuk kelompok 1 yang diberikan perlakuan sistim set diperoleh nilai tertinggi 6.0 meter, nilai terendah 3.2 meter, dan nila rata-ratanya adalah 4.60 meter. Sebaliknya untuk kelompok 2 yang diberikan perlakuan sistim sirkuit memperoleh nilai tertinggi 5.6 meter, nilai terendah 4.0 meter, dan nilai rataratanya adalah 4.78 meter. Dengan demikian dapat disimpulkan bahwa terdapat peningkatan daya ledak otot lengan pada kedua kelompok setelah diberikan perlakuan.S

\section{A. Pengujian Hipotesis}

Sebelum melakukan pengujian Hipotesis tentang sistem set $\left(\mathrm{X}_{1}\right)$ dan sitem sirkuit $\left(\mathrm{X}_{2}\right)$ terhadap terhadap peningkatan kemampuan daya ledak otot lengan

pada atlet bolabasket fik unp (Y) terlebih dahulu dilakukan uji persyaratan analisis yaitu uji normalitas sebaran data. Setelah data diuji dengan persyaratan analisis dilakukan uji Hipotesis.

\section{Uji Normalitas}

Uji normalitas data menggunakan Kolmogorov-Smirnov $\mathrm{Z}$ test, dan hasil yang diperoleh menunjukan bahwa data kedua kelompok berdistribusi normal yaitu $p>\alpha 0.05$. Untuk lebih jelasnya dapat dilihat pada tabel di bawah ini;

Tabel 5. Uji Normalitas Data

\begin{tabular}{|r|r|r|r|}
\hline & & $\begin{array}{r}\text { DOL } \\
\text { AWAL } \\
\text { SISTIM } \\
\text { SET }\end{array}$ & $\begin{array}{r}\text { DOL } \\
\text { AWAL } \\
\text { SISTIM } \\
\text { SIRUIT }\end{array}$ \\
\hline $\begin{array}{r}\text { Normal } \\
\text { Parameters }\end{array}$ & Mean & 4.390 & 4.390 \\
\hline & $\begin{array}{r}\text { Std. } \\
\text { Deviation }\end{array}$ & .631 & .538 \\
\hline $\begin{array}{r}\text { Most Extreme } \\
\text { Differences }\end{array}$ & Absolute & .168 & .166 \\
\hline & Positive & .131 & .166 \\
\hline \multicolumn{2}{|c|}{ Negative } & -.168 & -.095 \\
\hline $\begin{array}{r}\text { Kolmogorov- } \\
\text { Smirnov Z }\end{array}$ & .533 & .526 \\
\hline $\begin{array}{l}\text { a Test distribution is Normal. } \\
\text { b Calculated from data. }\end{array}$ & & \\
\hline \multicolumn{2}{|l|}{} & \\
\hline
\end{tabular}

\section{Uji Homogenitas}

Hasil uji homogenitas data dengan melalui uji varians, memperlihatkan bahwa data memiliki keragaman yang tidak berbeda dengan $p>\alpha$ 0.05. Dengan demikian dapat disimpulkan bahwa data awal kedua kelompok berada dalam keadaan homogeny.

Tabel 6. Uji Hemogenitas Varians Data Penelitian

Test of Homogeneity of Variances

\begin{tabular}{|r|r|r|r|r|r|}
\hline & & $\mathrm{N}$ & Correlation & Sig. & $\mathrm{t}$ \\
\hline Pair & DOL & 10 & .972 & .000 & 10.142 \\
1 & AWAL & & & & \\
& DAN & & & & \\
& AKHIR & & & & \\
& SISTIM & & & & \\
& SIRKUIT & & & & \\
\hline
\end{tabular}

3. Uji Hipotesis

a. Uji Hipotesis Satu (terdapat pengaruh yang signifikan latihan sistim set terhadap peningkatan daya ledak otot lengan )

Hasil analisis data dengan menggunakan uji t, menunjukan bahwa latihan sistim set tidak dapat meningkatkan daya ledak otot lengan dengan bermakna, yaitu $\mathrm{t}_{\text {hit }} 1.74<\mathrm{t}_{\text {tab }} 2.26$ dan $p 0.11>\alpha 0.05$, artinya tidak terdapat perbedaan antara hasil tes awal (pre-test) dengan tes akhir (posttest) setelah diberikan perlakuan latihan sistim set. Dengan demikian dapat disimpulkan bahwa $\mathrm{Ha}$ yang diajukan ditolak.

Tabel 7. Uji t DOL Awal dan Akhir Sistem Set

Paired Samples t-test

\begin{tabular}{|r|r|r|r|r|r|}
\hline & & $\mathrm{N}$ & Correlation & Sig. & $\mathrm{t}$ \\
\hline Pair & DOL & 10 & .864 & .116 & 1.741 \\
1 & AWAL & & & & \\
& dan & & & & \\
& AKHIR & & & & \\
& SISTIM & & & & \\
& SET & & & & \\
\hline
\end{tabular}

b. Hipotesis Kedua(Terdapat pengaruh yang signifikan latihan sistem sirkuit terhadap peningkatan daya ledak otot lengan)

Hasil analisis menunjukan bahwa; latihan sistim sirkuit dapat meningkatkan daya ledak otot lengan secara bermakna, yaitu $\mathrm{t}_{\text {hit }} 10.14>\mathrm{t}_{\text {tab }} 2.26$ dan $p 0.000<\alpha$ 0.05 . Ini dapat diartikan bahwa terdapat perbedaan yang signifikan antara hasil tes awal dengan hasil tes akhir pada kelompok 2 setelah diberikan perlakuan latihan sistim sirkuit. Hasil analisis tersebut dapat dilihat pada tabel di bawah berikut; 
Tabel 8. Uji t DOL Awal dan Akhir Sistim Sirkuit

Paired Samples t-test

c. Hipotesis ketiga(Terdapat perbedaan pengaruh yang signifikan antara latihan sistim set dengan sistim sirkuit terhadap peningkatan daya ledak otot lengan)

Hasil analisis data menunjukkan bahwa tidak terdapat perbedaan pengaruh yang signifikan antara latihan sistim set dengan sistim sirkuit terhadap peningkatan daya ledak otot lengan yaitu $\mathrm{t}_{\text {hit }} 1.132<\mathrm{t}_{\text {tab }} 2.26$ dan $p 0.287>\alpha$ 0.05. Dengan demikian dapat disimpulkan bahwa Ha yang diajukan dalam penelitian ini ditolak. Analisis data terhadap kedua kelompok dapat dilihat pada tabel berikut;

Tabel 9 Uji t DOL Akhir Sistem Set dan Sistem Sirkuit

\section{Paired Samples t-test}

\section{Pembahasan}

Sistem set merupakan salah satu metoda latihan melalui beberapa latihan yang tujuannya melihat kemampuan daya ledak otot lengan, untuk tercapainya tujuan tersebut latihan yang diberikan dipengaruhi oleh, intensitas, volume, repetisi dan recovery. dimana atlet diharuskan menyelesaikan suatu bentuk latihan di pos yang sama sampai 3 set tanpa pindah-pindah, setelah tiga set kemudian pindah ke pos berikutnya.

Sistem sirkuit merupakan salah satu bentuk latihan yang telah disusun sedemikian rupa, dimana atlet diharuskan menyelesaikan bentuk latihan pada satu pos kemudian pindah pada pos berikutnya sampai pos terakhir. Setelah menyelesaikan 1 set kemudian istirahat dan melakukan kembali sampai 3 set.

Daya ledak merupakan salah satu dari komponen biomotorik yang penting dalam kegiatan olahraga, karena daya ledak akan menentukan seberapa jauh melempar bola, sehingga otot harus mengerahkan tenaga dengan kuat dalam waktu yang singkat untuk memberikan momentum yang paling baik pada tubuh atau objek untuk membawa ke objek yang diinginkan.

Setelah dilakukan analisis data terhadap hasil penelitian dengan menggunakan analisis uji $t$ terhadap 3 hipotesis yang diajukan teruji secara empiris. Temuan penelitian seperti yang dikemukakan diatas merupakan hasil analisis secara statistic dan perlu dikaji sebagai berikut:

a. Sistim set tidak terdapat pengaruh yang signifikan terhadap peningkatan daya ledak otot lengan.
Sesuai dengan analisis data dapat dilihat $\mathrm{t}_{\text {hit }} 1,74<\mathrm{t}_{\text {tab }} 2,26$ dan $\mathrm{p} 0,11>\alpha 0,005$. hal ini berarti latihan sisitem set kurang dapat

\begin{tabular}{|r|r|r|r|r|r|}
\hline & & $\mathrm{N}$ & $\begin{array}{r}\text { Correlat } \\
\text { ion }\end{array}$ & Sig. & $\mathrm{t}$ \\
\hline Pair & DOL AWAL & 1 & .972 & .00 & 10.14 \\
1 & DAN & 0 & & 0 & 2 \\
& AKHIR & & & & \\
& SISTIM & & & & \\
& SIRKUIT & & & & \\
\hline
\end{tabular}

meningkatkan daya ledak otot lengan. Peneliti melihat kurangnya keseriusan orang coba melakukan gerakan, sehingga tdak terlihat peningkatan secara berarti.

Faktor lain yang dapat disimpulkan bahwa latihan sisitim set latihan yang tidak sistematis, menurut (Harsono 1993:2)"Sistematis berarti bahwa latihan dilaksanakan secara teratur, terencana, menurut jadwal, menurut pola dan berkesinambungan, jadi latihan yang tidak memenuhi salah satu atau lebi $\mathrm{h}$ pers yara $\tan$ ters

\begin{tabular}{|r|r|r|r|r|r|}
\hline & & $\mathrm{N}$ & Correlation & Sig. & $\mathrm{t}$ \\
\hline Pair & DOL & 10 & .751 & .287 & 1.132 \\
1 & AKHIR & & & & \\
& SISTIM & & & & \\
& SET \& & & & & \\
& SISTIM & & & & \\
& SIRKUIT & & & & \\
\hline
\end{tabular}

ebut maka latihannya tidak sistematis.

b. Sistem sirkuit terdapat pengaruh yang signifikan terhadap peningkatan daya ledak otot lengan.

Berdasarkan hasil pengujian hipotesis(2) menunjukkan bahwa latihan sistim sirkuit dapat meningkatkan daya ledak otot lengan. Dengan nilai thit 10,30 > ttab 2,26 dan $p$ $0,00<\alpha 0,05$ hal ini disebabkan orang coba melakukan gerakan secara serius dan juga masa istirahat dari pos kepos yang hanya 30 detik sehingga tampak terlihat peningkatan secara berarti.

Sesuai dengan prinsip latihan yang dikatan oleh (Fox 1988:25) suatu proses yang sistematis dalam menyiapkan atlet pada penampilan tingkat tinggi, proses dilakukan berulang-ulang dengan beban semakin meningkat. Dengan demikian dapat dikatakan latihan sisitim sirkuit dat meningkatkan daya ledak otot lengan.

c. Tidak terdapat perbedaan pengaruh antara sistem set dan sirkuit terhadap peningkatan daya ledak otot lengan.

Dari hipotesis (3) dapat dilihat dengan nilai thit $1,32<\operatorname{ttab} 2,26$ dan $\mathrm{p} 0,287>\alpha 0,05$ dengan demikian dapat disimpulkan latihan sisitim set dan sirkuit tidak terdapat perbedaan penyebabnya adalah kurang terlihatnya 
peningkatan dengan latihan 16 kali dan tidak terprogram secara jelas, maka tidak tampak perbedaan dari kedua metode latihan tersebut.

Agar latihan dapat dikatakan bagus seorang pelatih seharusnya memperhatikan lebih teliti saat melaksanakan perlakukan. Seperti yang dikatakan (Harsono 1993:11) yaitu

1. Latihan yang diberikan oleh pelatih adalah benar-benar bermanfaat dan sesuai dengan kebutuhan atlet.

2. Koreksi yang tepat dan kontruktif selalu diberikan manakala atlet melakukan kesalahan.

3. Pengawasan terhadap setiap detail gerakan dilakukan secara teliti.

4. Setiap kesalahan gerak segera diperbaiki.

\section{Kesimpulan}

Berdasarkan analisis data dan pembahasan di atas, maka penelitian dapat disimpulkan sebagai berikut:

1. Sistem set tidak terdapat pengaruh yang signifikan terhadap peningkatan daya ledak otot lengan dengan nilai $t_{\text {hit }} 1.74<$ $\mathrm{t}_{\text {tab }} 2.26$ dan $\mathrm{p} 0.11>0.05 \alpha$.

2. Sistim sirkuit terdapat pengaruh yang signifikan terhadap peningkatan daya ledak otot lengan dengan nilai $t_{\text {hit }} 10.30>$ $\mathrm{t}_{\mathrm{tab}} 2.26$ dan $\mathrm{p} 0.00<0.05 \alpha$.

3. Tidak terdapat perbedaan pengaruh yang signifikan antara metode latihan sistim set dan sistim sirkuit terhadap peningkatan daya ledak otot lengan dengan nilai $t_{\text {hit }}$ $1.32<\mathrm{t}_{\mathrm{tab}} 2.26$ dan $\mathrm{p} 0.287>0,05 \alpha$.

\section{DAFTAR PUSTAKA}

Afdal, M. (1991). Pengaruh latihan Kekuatan Sistem Set dan Sistem Sircuit Weight Training terhadap Kekuatan Otot pada Mahasiswa FPOK IKIP Padang, Tesis, IKIP Padang.

Ambler, VIC. (1982). Basketball (The basics For Coach and Player). London: Satelit Offset.

Arsil. (1999). Pembinaan Kondisi Fisik. Padang: FIK UNP.

Basoeki, Soejono. (1998). Anatomi dan Fisiologi Manusia. Jakarta : Depdikbud
Harsono. (1988). Coaching dan Aspek-aspek Psikologis dalam Coaching. Jakarta: P2LPTK.

Isparjadi (1988). Statistik Pendidikan. Jakarta : Depdikbud, Dikti : P2 LPTK.

Nawawi, Umar. (2008). Fisiologi Olahraga. Padang : FIK UNP.

Nurhasan. (1984). Tes dan Pengukuran Pendidikan Olahraga. Bandung : FPOK IKIP Bandung.

PB. PERBASI (2005). Bahan Penataran dan Penyegaran Bagi Pelatih Tingkat Dasar. Padang : Pengda Perbasi Sumbar.

PB. PERBASI .(2008). Pengaturan Permainan Bola Basket. Jakarta : PERBASI.

Sodikoen, Imam. (1992). Olahraga Pilihan Bolabasket. Padang : FPOK IKIP Padang.

Syafruddin. (1996). Pengantar Ilmu Melatih. Padang : FPOK IKIP Padang.

Syahara, Sayuti. (2005). Fisiologi Olahraga. Padang: Konsentrasi Manajemen Pendidikan Olahraga Pascasarjana UNP.

Tomoliyus. (2001). Pendekatan Keterampilan Taktis dalam Pembelajaran Bola Basket. (konsep dan metode). Jakarta : Depdiknas Dirjen Pendidikan Dasar dan Menengah dan Dirjen Olahraga.

Wawan Eko Yulianto. (2007). Dasar-dasar Bola Basket (terjemahan). Bandung : Pakar Raya.

Witarsyah. (2005). Bola Basket Pendalaman. Padang : FIK UNP.

Yendrizal. (1997). Pengaruh Latihan Beban dan Kemampuan Motorik Otot terhadap Kekuatan Otot. Tesis. Jakarta. 